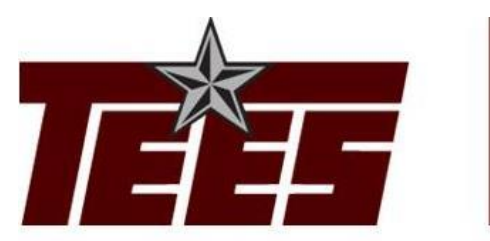

MARY KAY O'CONNOR PROCESS SAFETY CENTER

TEXAS A\&M ENGINEERING EXPERIMENT STATION

$19^{\text {th }}$ Annual International Symposium

October 25-27, 2016 • College Station, Texas

\title{
A Method to Utilize Facility Siting Techniques in the Early Phases of Capital Projects to Reduce Risks and Safety Spending
}

\author{
T. Anderson, P.E. and P. Hodge ${ }^{\dagger}$. \\ Mary Kay O'Connor Process Safety Center \\ Baker Engineering \& Risk Consultants, Inc. (BakerRisk $\left.{ }^{\circledR}\right)$ \\ 3330 Oakwell Court, Suite 100 \\ San Antonio, TX 78218-3024 \\ $\dagger$ Presenter E-mail: PHodge@BakerRisk.com
}

Keywords: Hazards, Risk, Facility, Layout, Siting, Building, Construction, Optimization, Fires, Explosions, Personnel, Capital Projects, Greenfield, Project Cost

\begin{abstract}
A common complaint when undertaking capital projects is the cost of engineered designs that must be added late in the project in order to mitigate hazards or risks. Due to the typical phasing of these project activities, the facility siting study (FSS) or other consequence or risk modeling is not completed until the layout of the facility has been established. When a site layout is already in a mature state; however, it can be extremely difficult to move hazards or populations to safer locations due to the substantial amount of rework that would be required. With mitigation through relocation thus limited or even unavailable, increasing the safety systems within the unit or adding layers of protection at the buildings of interest becomes the only option. Costs could be reduced and designs made safer if FSS or similar studies could be conducted earlier in the design process.

Moving the FSS up into the early design phases comes with its own hurdles, which often revolve around the lack of fully developed process information and a constantly changing facility layout. This requires that any FSS done in the early stages of design must be flexible and expedient to meet the rapidly evolving plant layout and process changes. This paper details a method for performing a FSS during the feasibility stages of a greenfield project through the creation of a design library of hazards and buildings that can be easily moved and edited.

This paper presents three case studies to explore examples of early mitigation of blast, fire, and toxic hazards, and provides examples of both consequence-based and risk-based decisions to be considered for each. A discussion of a basic cost saving analysis utilizing the FSS process is also explored. Through the use of FSS early in a design process, the capital project can create an
\end{abstract}


optimized design that meets both geographic constraints and corporate safety goals while providing a potential reduction in overall project cost.

\section{Introduction}

With a host of new markets to explore and an aging infrastructure, capital projects in the chemical and refining industries have increased in recent years [1]. As these projects move out of the design phase and into construction and commissioning, it is an excellent time to take stock of process safety lessons learned. One of the chief lessons is that incorporating process safety earlier in the process can allow for more freedom to make safety improvements to the project at a lower cost. A common complaint is that process safety can mandate changes late in the design or construction process of the project, which can lead to costly redesigns or expensive safety systems being added.

The natural response to this hurdle would be to move safety studies earlier in the design process, but this effort is often hindered by a lack of data. Process safety studies tend to rely on a highly specific mass of data that is often unavailable in the early stages of a project, or if the information is available early on, the project may be in such a state of flux that changes are occurring more quickly than the process safety engineer can assess the safety of the design. This can lead to a frustration among process safety, project management, and corporate management.

Though not a simple process, this frustration should lead us to pursue changes in both our project management and our process safety. Project managers may need to limit the number of design phases, increase the amount of time between designs, or prioritize acquiring certain process data. Process safety engineers on the other hand may need to learn to do more with less information by developing screening tools or decreasing the time taken on studies through increased efficiency.

This paper explores a variety of tools that can be implemented to move process safety studies earlier in the design process based on the authors' experience performing these studies for a wide range of capital projects. The examples provided focus on facility siting studies (FSS) and quantitative risk assessment (QRA) due to the author's familiarity with these topics, but the concepts inherent in them can be applied to other safety studies.

\section{Methodology}

Different information will be available at each stage in the design process. This section outlines the various phases of a typical capital project, along with the typical information that is available, and gives guidance on the level of study that can be performed at each stage of the analysis. A brief discussion on the limitations of the analysis and the assumptions that can be made is also provided.

\section{Establishing Design Criteria}

In the early stages of the project, the only information that may be available is a general scoping document that states the types of units to be constructed and the general site location for the project. 
At this time, the process safety engineer's first concern should be establishing a set of design requirements for the facility as well as making initial plans for the design library. Creating a design library is discussed in its own section below.

When gathering the set of project design requirements, the process safety engineer should consider the national and local standards that will be enforced. At this stage the location of the proposed project may not be fixed so establishing local guidelines may not be possible, but there may be mandated consequence or risk-based guidelines if a facility is to be built in the proposed jurisdiction. If these are present, the project team should ensure to allocate the appropriate resources and scheduling time to prove that the standards are met. For facility siting, key questions are societal risk posed by the plant to both the workers and the community, which typically takes the form of societal risk thresholds and land-use planning.

In addition to regulations and good engineering practices, the process safety engineer must also look at internal corporate standards that may also be written as consequence or risk-based approaches. It is important to examine these standards, as new construction may be subject to more rigorous standards than those applicable to existing plants. For example, it is not uncommon for existing buildings to be allowed a certain amount of risk of failure from blast overpressure, but then to require that new construction be designed to the maximum postulated blast loads in an area.

If there are no guidelines for tolerable consequences or risk, it may fall to the process safety engineer to assist project management and corporate HSE in establishing guidelines for the project. A variety of methods for establishing project criteria exist in the literature [2,3]. Having guidelines in place early in the project allows the process safety engineer to disqualify high risk designs or demonstrate the need for additional safety systems. Without knowing the design specifications for the capital project the process safety engineer will have difficulty in determining how much additional work needs to be done on a design to make it safe and how to provide consistent guidance.

\section{Creating a Design Library}

With design criteria in place, the process safety engineer can begin the work of modeling the project. At this time, it is unlikely that the project will have established more than the projected units, feedstocks, and products. As such, the process safety engineer needs to concentrate on tools and analysis that can provide relevant information with a paucity of data. A complete description of performing a FSS or QRA is not discussed in this paper, but a multitude of tools are available to assist the process safety engineer in performing such studies [4].

In the early stages, one of the most effective techniques involves creating process unit hazard or geographic risk contours that can then be moved around the available real estate of the project. These contours are assumed to be independent of one another at this stage, but they can serve as a general guideline of expected hazards or risks to the affected populations. The contours can assist project engineers as they plot locations for the units and can serve as an early warning of the types of mitigation efforts that may be needed if populations are to be placed near these units. It is important to note that different population types will have different hazardous endpoints of interest. Outdoor populations typically experience lower consequences from blast overpressure than do indoor populations. Toxic and thermal exposures are highly dependent on dosage 
(concentration exposure over time) and the prescribed emergency response plan. Offsite populations may have hazardous endpoints that are established by company, industry, or governmental requirements. As a result, the process safety engineer may need to develop more than one contour for a given unit in order to accurately assess the hazard to a given population.

If a similar unit has already been analyzed, developing contours for a unit of interest should be straightforward, and the unit can be placed into the model until more detailed information is available. Hazard contours can be developed to a high level of detail, and enough information may be available to pursue preliminary risk calculations. When using a previous design, the process safety engineer should consider removing any detailed refinements or mitigation efforts that were added to the model. Removing these systems will provide a better model of the baseline hazards and risks, unless these mitigation systems are standard practice to the proposed design.

If a similar unit has not been analyzed, the process safety engineer can still use the available information to create a temporary model. The engineer can use estimated maximum credible events to determine potential hazards from this unit. At this stage, it is unlikely that risk can be calculated with precision, but seasoned modelers may be able to calculate conservative estimates for frequency that can serve in the interim.

At this point in the process, the process safety engineer now has a unit model that can be adapted as new information becomes available, but still provide preliminary answers, especially from the facility layout perspective. The goal of the process safety engineer is to provide feedback to project engineers based on the current model and any current limitations of the model, and to update the model based on approved changes or additional information. Being aware of the limitations of the model is important at this step. Modelers should make conservative assumptions when needed and communicate these assumptions to the project engineers. As the project arrives at key decision points, the process safety engineer should be aware of what pieces of information are needed to perform the analysis as well as the limitations of the predictive power of the model. If conservative assumptions are not reassessed at later points, the project may make sub-optimal decisions in safety spending.

\section{Moving to FEED}

As the project moves into Front End Engineering Design (FEED) stages, more detailed information becomes available. At this point, an overall facility layout is typically established process safety engineer needs to have provided the majority of his overall layout commentary at this stage as it becomes increasing difficult to move the units. If the plot plan does change, the process safety engineer must be ready to change the working model quickly to demonstrate the effect of the anticipated changes on population areas.

As the overall facility layout becomes more fixed, it is important to look at the process unit independence assumption that was made during the preliminary analysis. Process units affect each other in a number of ways, including affecting pipe routing and blast calculations. Pipe routing is a fairly obvious assessment that needs to occur. Although pipelines are often thought of being highly reliable systems, failures do occur and pipelines often introduce hazards to otherwise "safe" locations. While the exact route of the piperack may not be established at this point, the process 
safety engineer can begin a dialogue with the piping team to ensure that safety is being considered during this process. In addition, simple standoff distances can be calculated based on the expected pipeline conditions.

Performing blast hazard calculations can also become more difficult at this stage of design. In addition to the blast hazards from the given unit, the process safety engineer must also consider the possibility of a flammable cloud from a neighboring unit entering the unit, igniting, and causing a blast overpressure event. This can cause units with no to very low internally-caused blast hazards to have blast overpressure hazards originating from within them. The presence of pipelines further increases the chance of this occurring as the piperack may bring flammable materials to otherwise low-hazard parts of the plant. Even if a process safety engineer is not able to explicitly calculate the blast overpressures from these types of events, the use of a flammable limit contour should show the overlap of flammable clouds and other units, which can trigger the need for a more detailed blast calculation if parts of the plant that were not subject to a flammable cloud previously are being affected.

Another key decision during the FEED stage of the project is to determine when to perform a more detailed assessment of the units. For the process safety engineer performing a FSS, there are two triggers to consider. The first is the creation of the process flow diagrams (PFDs) and associated heat and material balances (H\&MBs). The second is the completion of the unit process hazard analysis (PHA) or similar analysis. The benefit of performing a significant update to the model with the rollout of PFDs is that the majority of the information needed to perform a more detailed FSS is now available. Simplifying assumptions can be confirmed or refined and the model that initially included only a handful of scenarios can be augmented with a more representative set of hazards. Performing risk calculations becomes much more feasible as well. Other studies, such as the PHA, can also benefit from the information available from the FSS.

The downside is that the information is still in flux and details on inventories, detection, targets of concern, etc. may not yet be available. This flux may cause some projects to postpone the more detailed assessment until after the PHA is performed. The PHA or similar analysis will often trigger a freeze in the iteration of process drawings in order for key studies to be completed. Many of these documents are vital to performing a detailed FSS, which allows the process safety engineer a space of time without significant changes to devote to updating the model. In addition, the PHA may spawn many revisions to a unit that must be incorporated into the model. Waiting means that the project is allowed to progress further without an update to the underlying assumptions, which may increase the amount of redesign needed as well as more significant management of change (MOC) procedures.

The decision of when to perform the FSS update will typically be a function of the time available between release of a preliminary set of full PFDs and the PHA, the amount of time available to the process safety engineer to perform rework, the level of assumption made during the preliminary analysis, and the desire for FSS information during the PHA. Larger projects may even elect to perform significant updates during both of these time periods.

\section{$\underline{\text { Building Considerations }}$}


During FEED, the project often begins to establish probable locations for key buildings and outdoor work areas. Depending on the level of detail available, the process safety engineer may be able to begin calculating specific hazardous endpoints or risks that will impact these buildings. While most project engineers will recognize that various building designs will respond to blast hazards differently, early in the project they may not recognize that the buildings may respond differently to toxic and fire hazards. As such it is critical for the process safety engineer to communicate this information. A common method of doing this is to create a common library of plant buildings.

Several common building construction types that meet minimum environmental design requirements for the region of interest can be established. These building construction types should be based on a well-established minimum design-basis and could even be based on existing vendor-supplied products. In general, these building construction types will be established without any specific consideration for process hazards and will represent the minimal relative construction costs that building construction and location decisions can be based on. Construction types could include those common to control rooms, administration buildings, warehouses, maintenance shops, motor control centers (MCCs), mobile offices, etc. Detailed methodologies for making these building models can be found in the literature [5].

Once these building types have been modeled, the process safety engineer may develop plantwide contours specific to several different generic types of buildings. The goal is to show how different locations may be considered safe depending on the additional mitigation added to the building (typically at an increased cost). This concept is explored further in the maintenance shop case study below. One danger of this methodology is having an overabundance of contours such that the project engineer has difficulty in using them effectively.

If a specific location has been chosen for a particular building, another option is to perform a feasibility level design. A feasibility study considers several different building construction types and mitigation plans, based on either hazards or risks, and can quickly demonstrate the gains in safety for the location as the building costs are increased. Based on the project risk tolerances established at the beginning of the project, the team can determine if one of the building designs meets the objectives for an acceptable cost or if an alternative location should be pursued. This is explored more in the control room case study below.

In addition to on-site buildings and population areas, individual pieces of equipment (especially long lead-time replacement items), structures that house equipment, and systems (e.g., cooling towers, the fire water pump house structure, and the power distribution system) that are critical to safety or business interruption can be identified. Threshold limits for functionality and/or damage can be established; damage and functionality can also be linked in order to assess any hazard impacts on a risk basis. More detailed explanations of this technique can be found in the literature [6].

\section{$\underline{\text { Revisiting Assumptions in Detailed Design and Beyond }}$}

At the end of FEED, the process safety engineer should have an FSS model that reflects both the agreed upon layout of the facility as well as the specifics of each process unit's processes. 
Depending on when the FEED update of the model was performed, the process safety engineer may need to perform an update of the model at this point. Either way, an established baseline should be available as the project moves into detailed design.

Detailed design is often an area of relative comfort for the process safety engineer who is typically used to working in this area, as the vast majority of the data required is now available and fixed. Also, at this stage, mitigation options are typically added to the design of the project. If the process safety engineer has been effectively working with the project team, the need for mitigation and the related sensitivity studies should be known to the team. This allows project managers to include these studies in both time and cost estimates up front instead of adding them on the back end.

At this stage, the process safety engineer often has to juggle multiple smaller studies as project engineers zero in on the specifics of certain design elements. Also, as mitigation options are finalized and assumptions validated, the process safety engineer may be able to communicate that less extensive safety measures will be needed. This is good, as cost-cutting is often a key step in detailed design. It is up to the process safety engineer to help the project team identify what mitigation efforts and safety systems are providing key value to the project and which can be eliminated. As cost cutting and final design are being pursued, it is imperative that MOC procedures are followed to avoid costly last-minute surprises for the project team.

As the project enters construction and commissioning, the process safety engineer should transition their focus to MOC and specific construction hazards. Locations of temporary buildings (typically used by third-party contractors) and the changing hazard portfolio as new units are constructed and brought online are key safety issues during this phase that can be informed by the FSS. Changes to the design at this phase should include input from the process safety engineer as a key step in the MOC. One of the final roles of the project's process safety engineer is a handoff of the model and results of the study to the operating safety engineer. This will allow the operating safety engineer to keep the study evergreen as changes are inevitably made during operation.

\section{Case Studies}

The following case studies utilize the methods outlined above. The three case studies revolve around land use, unit location, building siting, and building hazard mitigation.

\section{$\underline{\text { Unit Location }}$}

In this case study, a project is in the feasibility stages of adding three new process units to an existing plant. Unit A has high blast hazards, Unit B has high toxic hazards, and Unit $\mathrm{C}$ has negligible hazards. The current plant's plot plan is provided in Figure 1 below. A public road runs to the north of the plant, and farmland borders the plant to the east. An existing control room (CR3) is shown on the map as well. The project team proposes the layout shown in Figure 2, based on synergies with the existing plant. Corporate guidelines suggest limiting blast overpressure hazards to $1 \mathrm{psi}$ at the site boundary. 


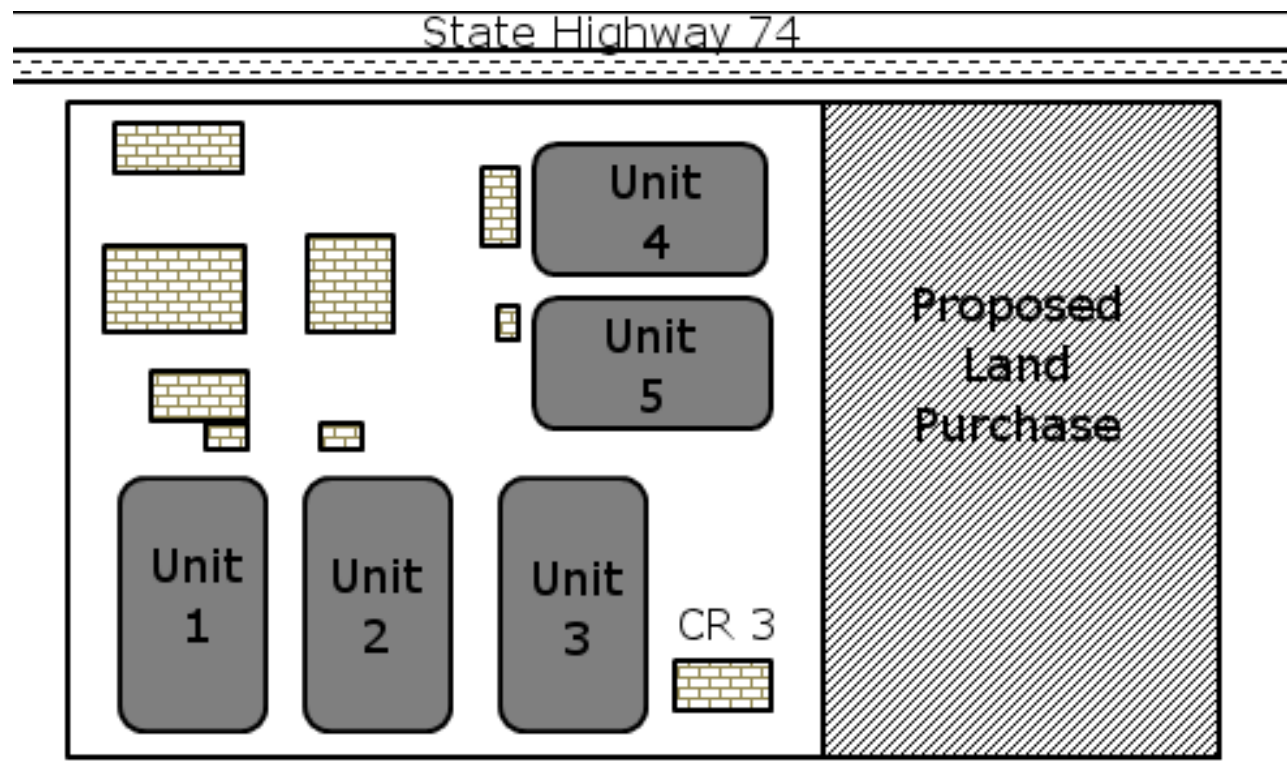

Figure 1. Current Plant Plot Plan

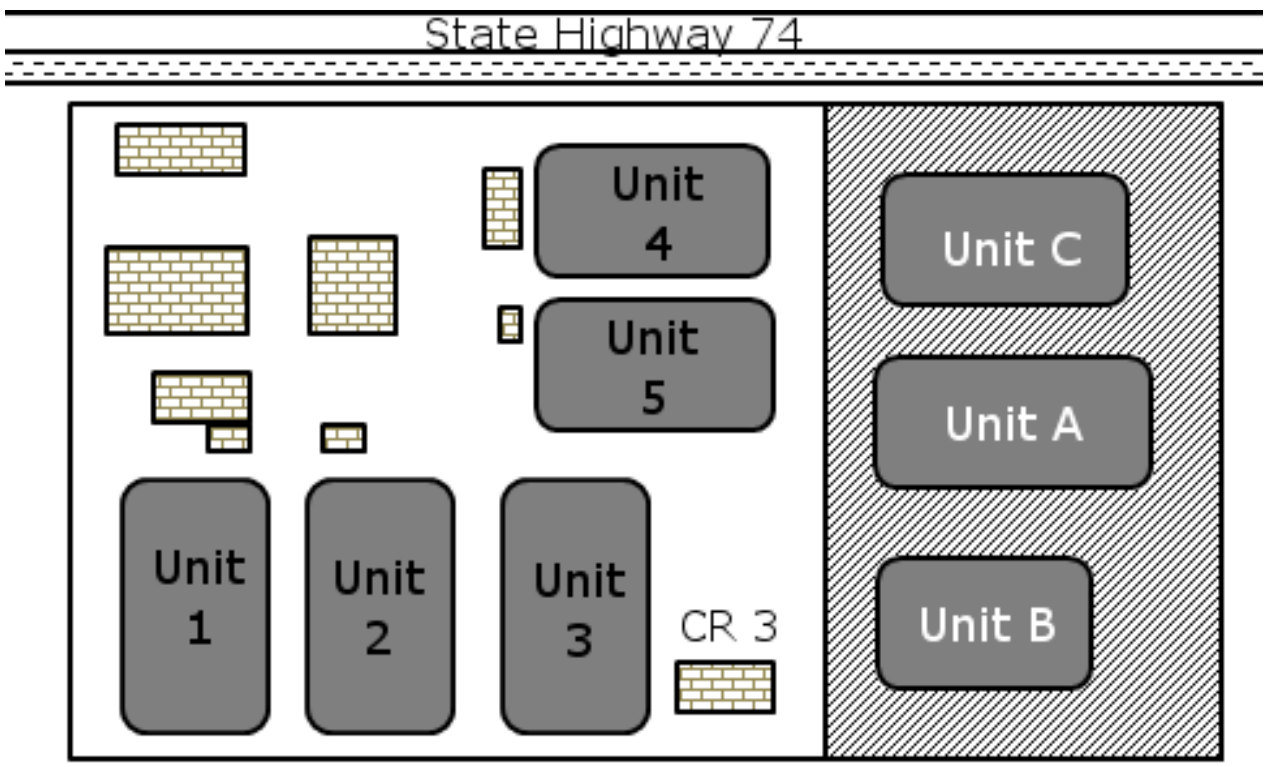

Figure 2. Proposed Layout

The process safety engineer starts the analysis by building a design library. Unit A can be modeled based on an existing plant unit. Although there will be some changes to the new unit, the process safety engineer elects to use the existing unit model for the moment. Unit B is the first of its kind for the company and the process safety engineer does not have detailed information about the hazards in the unit. The process safety engineer chooses to use the product pump conditions for a maximum credible hazard at this stage. Unsure of the orientation of the unit, the process safety engineer originates the hazard at several locations around the proposed battery limit of the unit. Unit $\mathrm{C}$ has negligible hazards so is not modeled. The process safety engineer calculates the 
blast overpressure (at $1 \mathrm{psi}$ ), flash fire (at the lower flammable limit), and toxic endpoints (90\% lethality for a 1 minute exposure) and overlays them on the current proposed unit layout as detailed in Figure 3 through Figure 5 respectively.

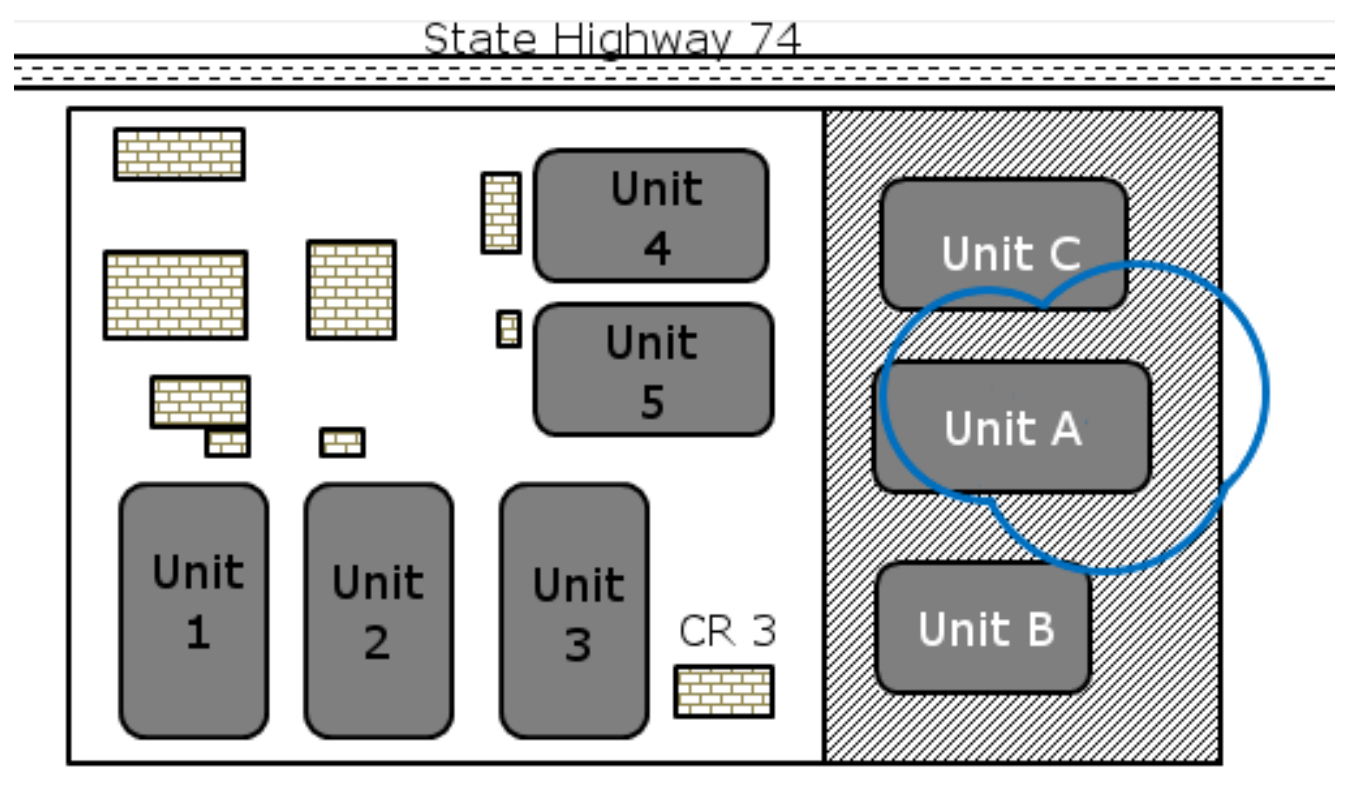

Figure 3. Proposed Layout Blast Overpressure

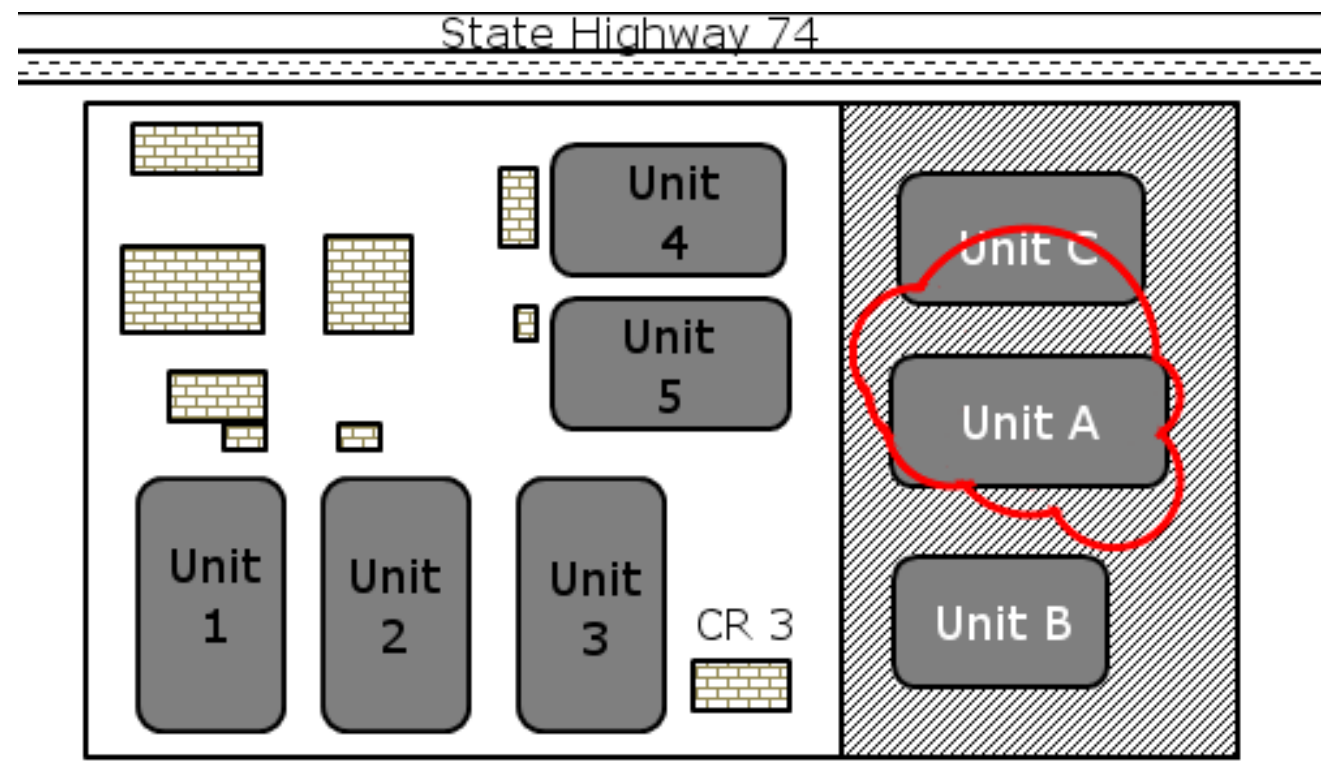

Figure 4. Proposed Layout Lower Flammable Limit 


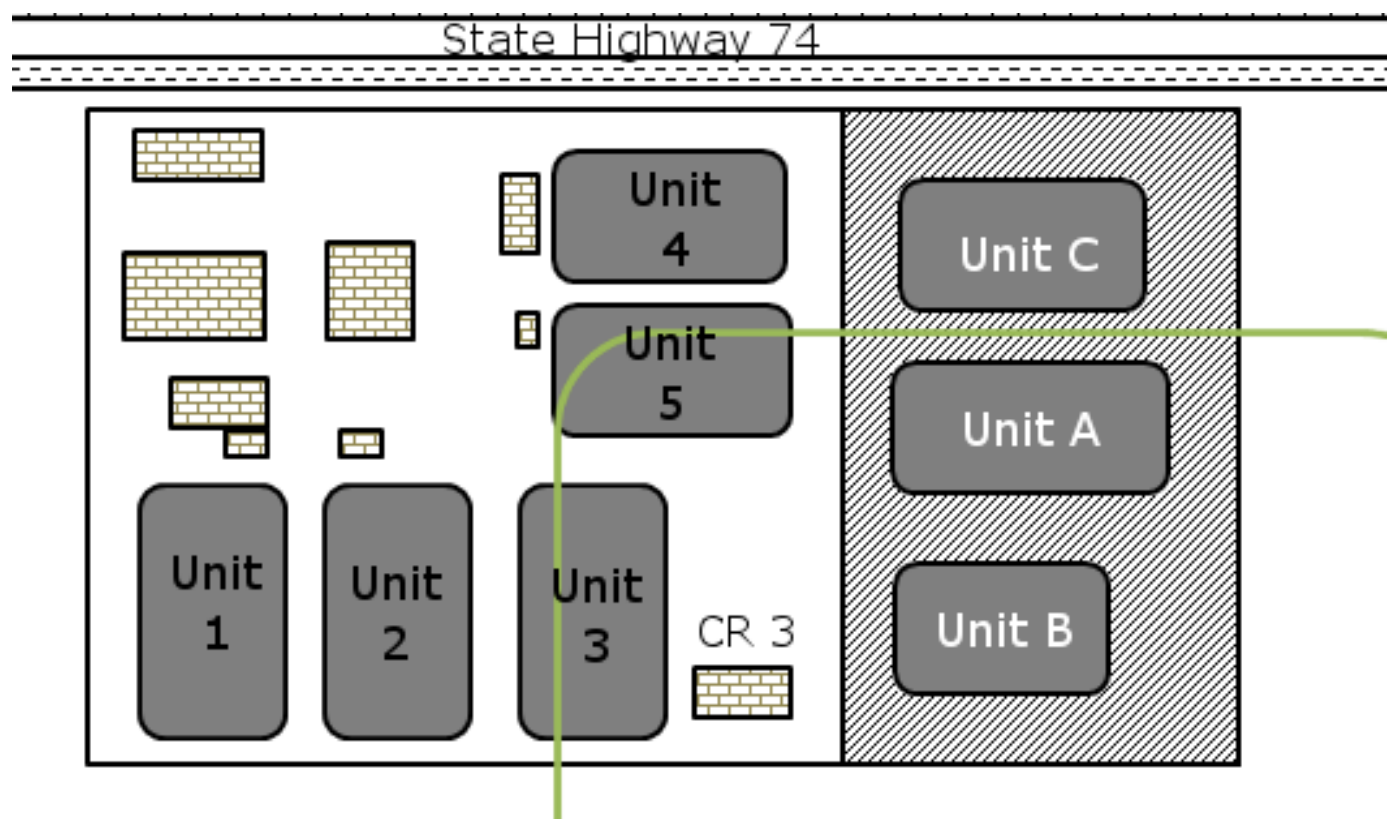

Figure 5. Proposed Layout Toxic Contour (90\% Lethality 1 min. Exposure)

The process safety engineer notes that based on this preliminary analysis, the blast overpressure exceeds 1 psi to the east only, but the flammable limit contour of Unit A covers a portion of Unit B. The process safety engineer knows that additional blast overpressure may be generated if the cloud ignites inside Unit B, so an additional blast calculation is performed to generate updated blast overpressure endpoints of interest (see Figure 6). There is now significant blast overpressure predicted to the road to the north.



Figure 6. Proposed Layout Adjusted Blast Contours 
To account for this, the process safety engineer proposes an alternate layout in Figure 7 with the new blast contours and flammable limits added. This eliminates the blast hazards on the road to the north, but loses the efficiencies of tying into the existing piperack. The project will need to determine if the alternate layout is a significant enough safety benefit for the additional cost, or plan to look into other methods of controlling the blast overpressure hazard to the road.

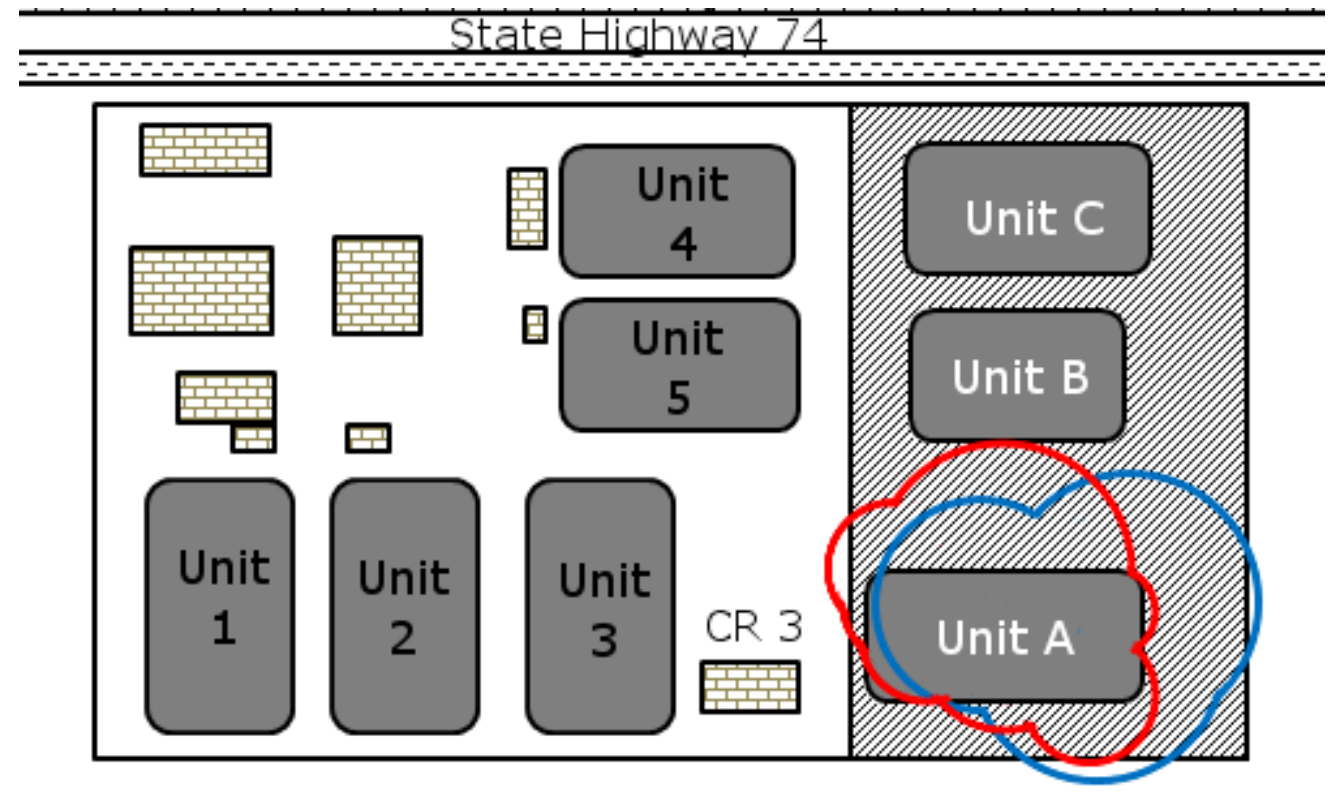

Figure 7. Alternate Layout with Blast Overpressure and Flammable Limits

Another key decision point for the project is the land to the east. If the project does not want the 1 psi blast overpressure to propagate offsite, purchase of additional land must be budgeted to ensure that this buffer is in place, or alternate means of controlling the hazard must be reviewed. Another consideration is the toxic exposure from Unit B to the existing control room. The project should assess if the presence of Unit B will require additional mitigation measures at the control room.

While a detailed assessment of the requirements for mitigation may not be available until later design stages, the process safety engineer can identify this possibility early in the preliminary layout in order to budget for the additional studies and the potential mitigation devices.

\section{Maintenance Shop Siting}

In this case study, consider that the site owner would like to place a maintenance shop within close proximity to a process unit, as shown in Figure 8, and that the main hazard of concern is blast loading. Using a pre-defined building construction type for the maintenance shop (based on a well-established minimum design-basis with a minimal relative construction cost), a contour of constant damage due to the postulated blast loading can be generated around the new process unit, based on the site owner's tolerable level of damage. By increasing the blast capacities of the typical building components used to develop the initial building construction type's structural 
model, additional contours of constant blast damage can also be generated. In this way, the design requirements for the maintenance shop at the owner's preferred location can be established. In addition, the cost for the building construction type at the owner's preferred location relative to the minimum design-basis can be established.

By generating constant blast damage contours relative to the new process unit, and varying any single building parameter (e.g., blast capacity, construction type and/or cost), comparisons between options can then rapidly be made by the owner. For example, a comparison between cost and distance can be made on the basis of the time that personnel would need on a daily basis to travel the additional distance between the process unit and the building and the initial building construction cost. Other cost items, such as the cost of building utilities between locations, can also be similarly considered. Note that constant response contours can also be established for other hazards, such as thermal or toxics, to allow similar comparisons.

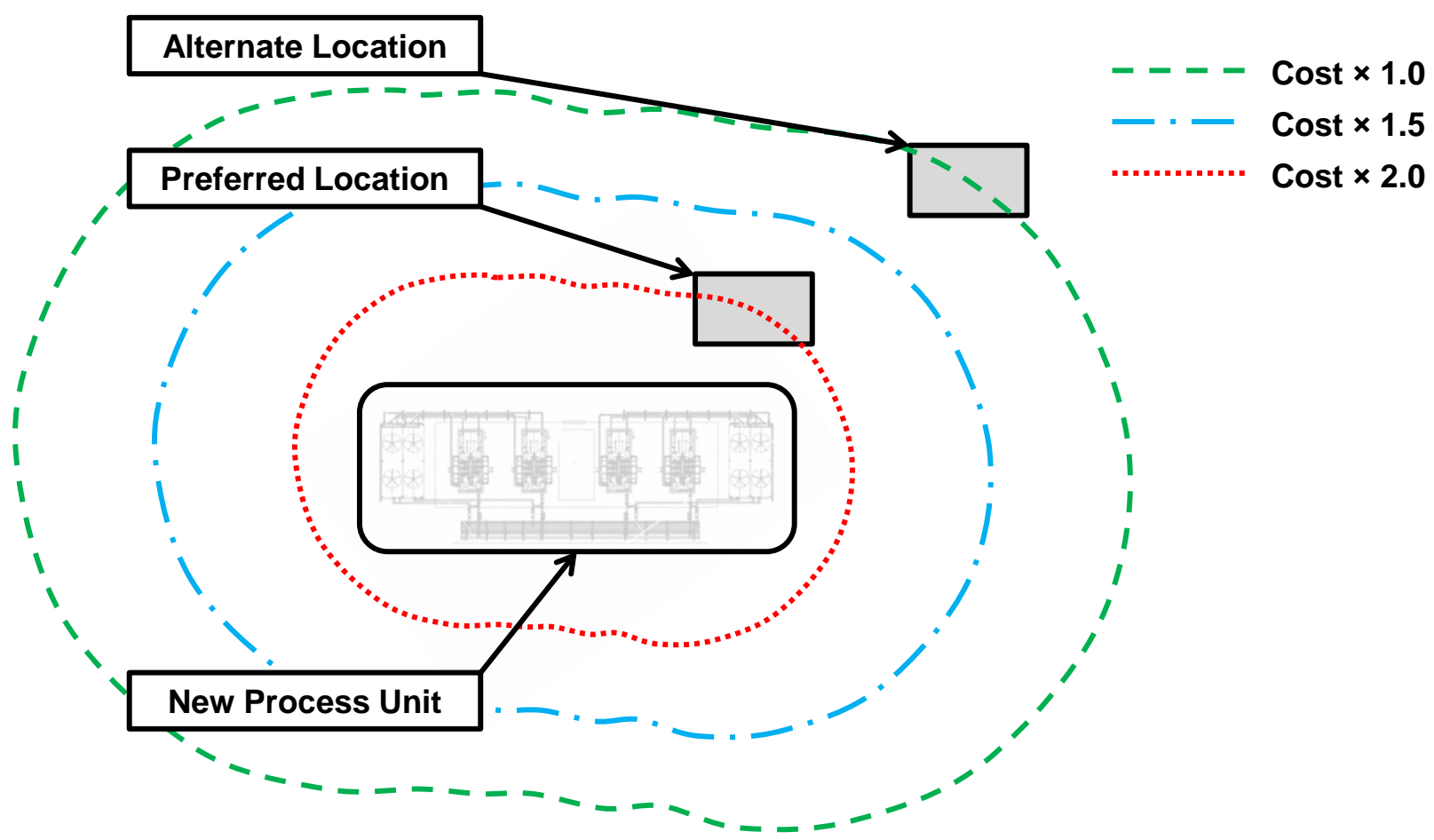

Figure 8. Example Maintenance Shop Location Options

This can similarly be performed based on a risk approach, as introduced by others [6]; however, the likelihood that the result may change over the course of the assessment may be increased due to the number of variables that need to be defined prior to performing the assessment. Therefore, it may be prudent to be conservative in the initial definition of the variables, allowing the study to be refined as more detailed information becomes available.

\section{Control Room Hazard Mitigation}

In this case study, during the FEED stage, a project is adding two new identical process units as shown in Figure 9. The site owner would like to place a control room within close proximity to the process areas that would service the process units and house essential personnel. The owner 
needs to provide a certain square footage of building space that would service both process units and house all essential personnel. Two options are provided: either use one larger building (i.e., control room option "A" as shown in Figure 9) or split the space into two smaller buildings (i.e., control room options "B1" and "B2" as shown in Figure 9); the smaller buildings would each house half the essential personnel. The overall dimensions and square footage of the new control room options are shown in Table 1.

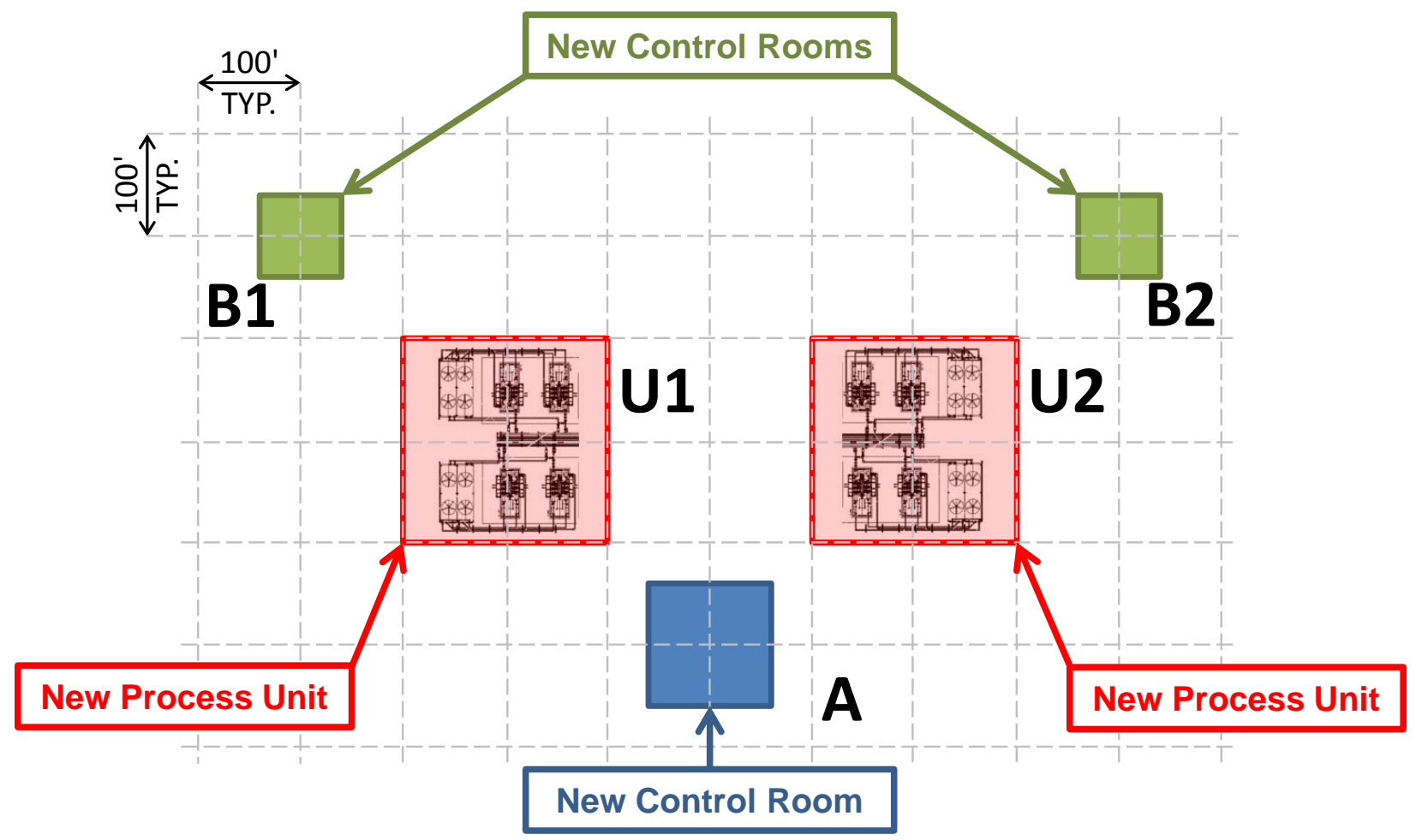

Figure 9. Proposed Process Unit Layout with Control Room Options

Table 1. Control Room Options

\begin{tabular}{|c|c|c|c|}
\hline $\begin{array}{c}\text { Control Room } \\
\text { Option }\end{array}$ & $\begin{array}{c}\text { Dimensions } \\
(\mathbf{f t} \times \mathbf{f t})\end{array}$ & $\begin{array}{c}\text { Floor Area } \\
\left(\mathbf{f t}^{2}\right)\end{array}$ & $\begin{array}{c}\text { Relative } \\
\text { Occupancy }\end{array}$ \\
\hline A & $120 \times 120$ & 14,400 & 1.0 \\
\hline B1 & $85 \times 85$ & 7,225 & 0.5 \\
\hline B2 & $85 \times 85$ & 7,225 & 0.5 \\
\hline
\end{tabular}

The site owner's corporate policies allow for the use of a risk-based methodology to site and design new buildings and recommend that multiple construction options are considered, as shown in Table 2. The site owner also needs to know what the cost implications would be if the new buildings are designed to have a limited response to the maximum postulated blast loading (i.e., following a consequence-based methodology). This would allow the site owner to determine how to allocate resources in a cost effective manner while meeting safety goals. 
Table 2. Construction Type Options and Approximate Structural Materials Cost

\begin{tabular}{|c|c|c|c|}
\hline $\begin{array}{c}\text { Construction } \\
\text { Type }\end{array}$ & $\begin{array}{c}\text { Design } \\
\text { Methodology }\end{array}$ & $\begin{array}{l}\text { Dimensions } \\
(\mathbf{f t} \times \mathbf{f t})\end{array}$ & $\begin{array}{c}\text { Approximate Structural } \\
\text { Materials Cost } \\
\left(\$ / \mathbf{f t}^{2}\right)^{\ddagger}\end{array}$ \\
\hline \multirow{4}{*}{$\begin{array}{l}\text { Precast Concrete } \\
\text { with Steel Frame }\end{array}$} & \multirow{2}{*}{ Consequence } & $120 \times 120$ & 50 \\
\hline & & $85 \times 85$ & 70 \\
\hline & \multirow{2}{*}{ Risk } & $120 \times 120$ & 40 \\
\hline & & $85 \times 85$ & 60 \\
\hline \multirow{4}{*}{$\begin{array}{l}\text { Pre-Engineered } \\
\text { Metal Building }\end{array}$} & \multirow{2}{*}{ Consequence } & $120 \times 120$ & 30 \\
\hline & & $85 \times 85$ & 35 \\
\hline & \multirow{2}{*}{ Risk } & $120 \times 120$ & 20 \\
\hline & & $85 \times 85$ & 25 \\
\hline
\end{tabular}

Since the process units being considered are identical, the potential blast hazards (and their frequency of occurrence) would also be identical. Given the optional locations of the control room options, shown in Figure 9, the standoff distance (from the center of each process unit to the center of each building) and the maximum postulated blast loading would be as shown in Table 3. Note that the controlling maximum blast loading (i.e., the maximum used in a consequence-based design) is the same for each control room option; however, the larger standoff distance between a given process unit and the smaller building located on the opposite side of the adjacent process unit results in a significant reduction in the maximum postulated blast loading originating in that given process unit. In addition, the maximum postulated blast loading from both process units is the same at the larger building. It would, therefore, be evident that the resulting blast risk, for buildings with the same construction type, would be lower at each smaller building location (i.e., control room option "B1" or "B2" as shown in Figure 9) than at the larger building location (i.e., control room option "A" as shown in Figure 9).

Table 3. Maximum Postulated Blast Loading

\begin{tabular}{|c|c|c|c|c|}
\hline $\begin{array}{c}\text { Process } \\
\text { Unit/Source }\end{array}$ & $\begin{array}{c}\text { Control Room } \\
\text { Option/Receptor }\end{array}$ & $\begin{array}{c}\text { Standoff Distance } \\
\text { (ft) }\end{array}$ & $\begin{array}{c}\text { Pressure } \\
\text { (psi) }\end{array}$ & $\begin{array}{c}\text { Impulse } \\
\text { (psi-ms) }\end{array}$ \\
\hline U1 & A & 283 & 2.4 & 225 \\
\hline U2 & A & 283 & 2.4 & 225 \\
\hline U1 & B1 & 283 & 2.4 & 225 \\
\hline U2 & B1 & 632 & 1.2 & 102 \\
\hline U1 & B2 & 632 & 1.2 & 102 \\
\hline U2 & B2 & 283 & 2.4 & 225 \\
\hline
\end{tabular}

Given the maximum postulated blast loading (including their frequency of occurrence), the construction types being considered, the building occupancies, the resulting personnel vulnerabilities, and the design methodology bases (i.e., risk- or consequence-based), the control room options presented in this example can be compared in a relative manner, as follows:

1. The control room options, using the Precast Concrete with Steel Frame construction type, can be compared using the risk-based design of the larger building as the basis. The results 
of this comparison are summarized in Table 4 and shown graphically in Figure 10. In this example, the site owner can achieve a $50 \%$ reduction in the blast risk if two smaller buildings are utilized instead of one larger building but this adds a 50\% increase in structural materials cost. Further risk reduction can be achieved by using a consequencebased design. For the larger building, the site owner can achieve a $99 \%$ reduction in the blast risk with only a $30 \%$ increase in structural materials cost. Even further risk reduction can be achieved by utilizing the same consequence-based design for the two smaller buildings, but with an $80 \%$ increase in structural materials cost.

Table 4. Precast Concrete with Steel Frame Construction Type Options Comparison

\begin{tabular}{|c|c|c|c|c|}
\hline $\begin{array}{c}\text { Construction } \\
\text { Type }\end{array}$ & $\begin{array}{c}\text { Design } \\
\text { Methodology }\end{array}$ & $\begin{array}{c}\text { Dimensions } \\
(\mathbf{f t} \times \mathbf{f t})\end{array}$ & Risk Ratio & $\begin{array}{c}\text { Material Cost } \\
\text { Index }\end{array}$ \\
\hline \multirow{2}{*}{$\begin{array}{c}\text { Precast } \\
\text { Concrete with } \\
\text { Steel Frame }\end{array}$} & Risk & $120 \times 120$ & 1.0 & 1.0 \\
\cline { 3 - 5 } & Consequence & $85 \times 85$ & 0.5 & 1.5 \\
\cline { 3 - 5 } & & $85 \times 85$ & 0.005 & 1.3 \\
\hline
\end{tabular}

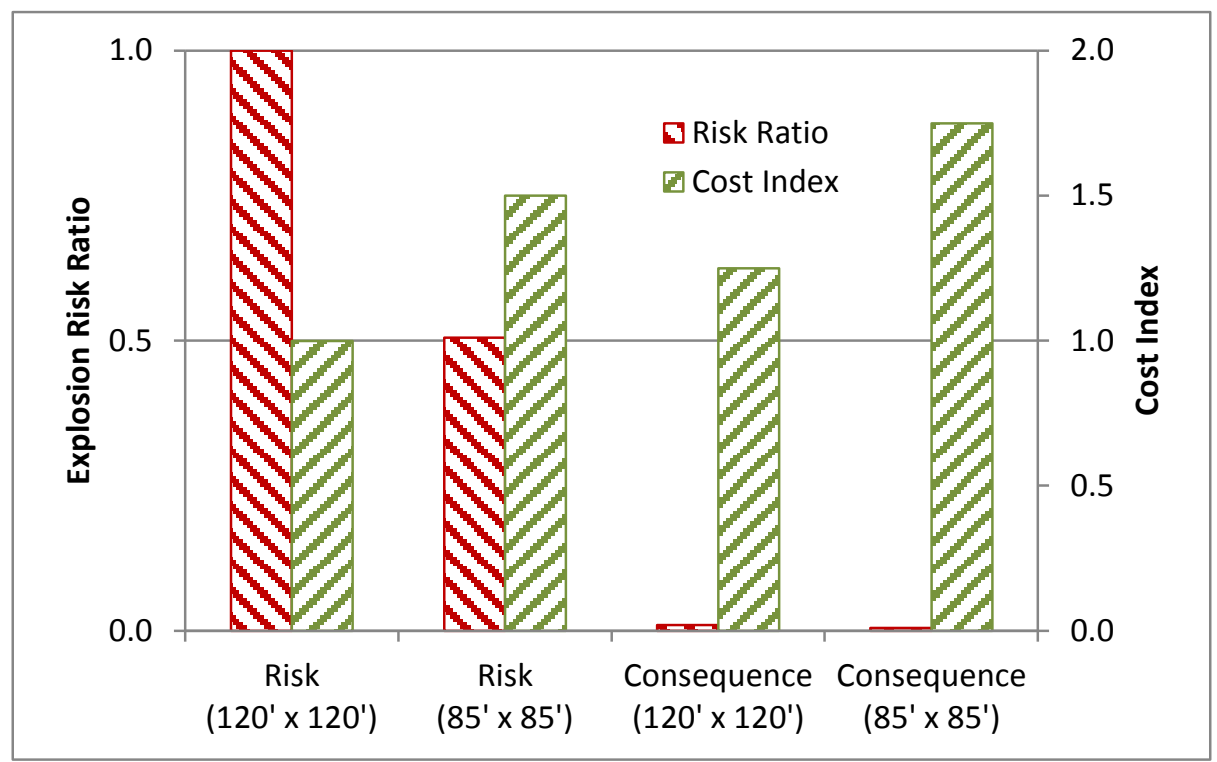

\section{Figure 10. Comparison of Precast Concrete with Steel Frame Construction Type Options}

2. Similarly, for the control room options, using the Pre-Engineered Metal Building construction type can also be relatively compared using the risk-based design of the larger building as the basis. The results of this comparison are summarized in Table 5 and are shown graphically in Figure 11. In this example, the site owner can achieve a $15 \%$ reduction in the blast risk if two smaller buildings are utilized instead of one larger building but with a $30 \%$ increase in structural materials cost. Further risk reduction can be achieved by using a consequence-based design. For either the larger building or two smaller buildings, the site owner can achieve a near elimination of the blast risk with either a $50 \%$ or $80 \%$ increase in structural materials cost, respectively. 
Table 5. Pre-Engineered Metal Building Construction Type Options Comparison

\begin{tabular}{|c|c|c|c|c|}
\hline $\begin{array}{c}\text { Construction } \\
\text { Type }\end{array}$ & $\begin{array}{c}\text { Design } \\
\text { Methodology }\end{array}$ & $\begin{array}{c}\text { Dimensions } \\
(\mathbf{f t} \times \mathbf{f t})\end{array}$ & Risk Ratio & $\begin{array}{c}\text { Material Cost } \\
\text { Index }\end{array}$ \\
\hline \multirow{2}{*}{$\begin{array}{c}\text { Pre- } \\
\text { Engineered } \\
\text { Metal } \\
\text { Building }\end{array}$} & \multirow{2}{*}{ Risk } & $120 \times 120$ & 1.0 & 1.0 \\
\cline { 3 - 5 } & Consequence & $85 \times 85$ & 0.85 & 1.3 \\
\cline { 3 - 5 } & & $85 \times 85$ & $<0.001$ & 1.5 \\
\hline
\end{tabular}

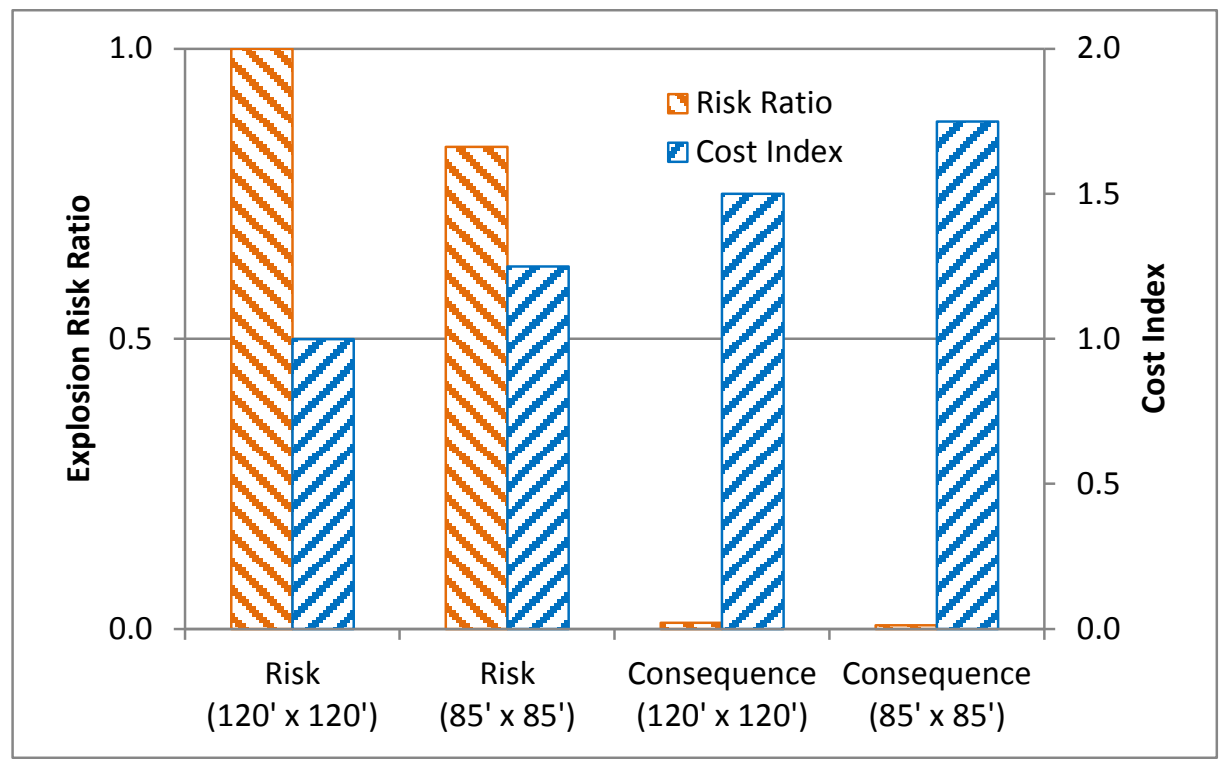

Figure 11. Comparison of Pre-Engineered Metal Building Options

3. All of the risk-based design options for the control room options can be relatively compared using the larger Pre-Engineered Metal Building construction type building as a basis. The results of this comparison are summarized in Table 6 and are shown graphically in Figure 12. In this example, the site owner can achieve a $15 \%$ reduction in the blast risk if two smaller buildings are utilized instead of one larger building, with only a $30 \%$ increase in structural materials cost. Given the higher potential for vulnerability in the Precast Concrete with Steel Frame construction type, the blast risk can actually be increased by $50 \%$ by changing the construction type, resulting in a $100 \%$ increase in relative structural material cost. However, the greatest risk reduction can be achieved by using two smaller Precast Concrete with Steel Frame construction type buildings instead of one larger PreEngineered Metal Building construction type building; a 25\% reduction in the blast risk can be achieved, with a $200 \%$ increase in structural materials cost. In many cases, the more costly building construction type may be more desirable, given that other hazards (such as thermal hazards) may also be a consideration. Armed with the above comparisons, the site owner is able to make a well-informed decision regarding the choice of location, design and construction type of the new control room or rooms. 
Table 6. New Risk-Based Building Options Comparison

\begin{tabular}{|c|c|c|c|}
\hline $\begin{array}{c}\text { Construction } \\
\text { Type }\end{array}$ & $\begin{array}{c}\text { Dimensions } \\
(\mathbf{f t} \times \mathbf{f t})\end{array}$ & Risk Ratio & $\begin{array}{c}\text { Material Cost } \\
\text { Index }\end{array}$ \\
\hline $\begin{array}{c}\text { Pre- } \\
\text { Engineered } \\
\text { Metal Building }\end{array}$ & $120 \times 120$ & 1.0 & 1.0 \\
\cline { 2 - 4 } & $85 \times 85$ & 0.85 & 1.3 \\
\hline $\begin{array}{c}\text { Precast } \\
\text { Concrete with } \\
\text { Steel Frame }\end{array}$ & $120 \times 120$ & 1.5 & 2.0 \\
\cline { 2 - 4 } & $85 \times 85$ & 0.75 & 3.0 \\
\hline
\end{tabular}

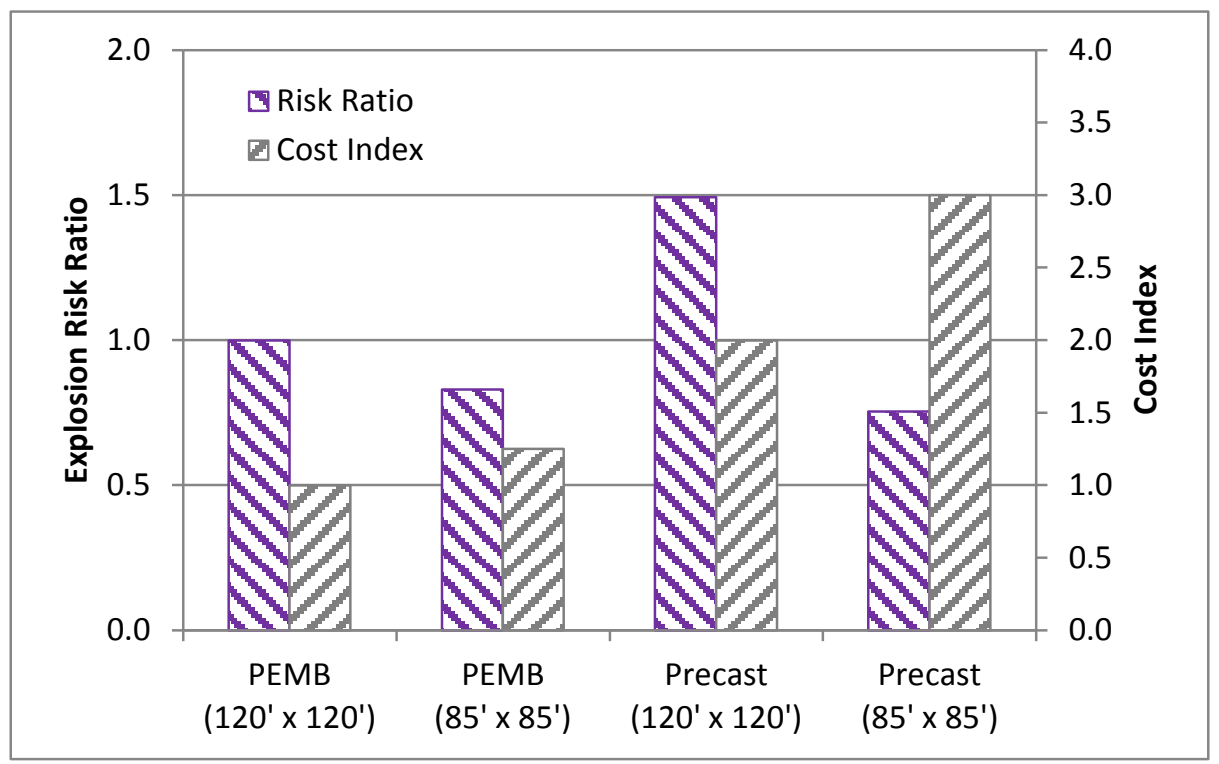

Figure 12. Comparison of New Risk-Based Building Options

\section{Conclusions}

Encouraging the process safety engineer to begin modeling and assessing potential hazards and risks early in a project can provide for a much more transparent implementation of process safety throughout the design process. Facilitating design changes early on will save on costly redesigns in detailed design while also setting the expectation for needed safety and mitigation systems to aid in planning. The original design may still be implemented, but the project will be aware that an increased cost of construction may be needed. Using FSS and QRA techniques early in a design process can create an optimized design that meets geographic constraints and corporate safety goals while providing a potential reduction in the overall cost of a capital project.

\section{References}

1. Elliot, A.R., "Shale Gas 2.0: A Follow-On Boom In The U.S. Chemicals Trade," Investor's Business Daily, Los Angeles, September 2, 2016

2. CCPS, "Guidelines for Developing Quantitative Safety Risk Criteria," American Institute of Chemical Engineers Center for Chemical Process Safety, New York, 2009

3. Shah, J., "Understanding and Developing Quantitative Risk Criteria," submitted to the 8th Global Congress on Process Safety: 2012 Spring Meeting, April 2012 
4. CCPS, "Guidelines for Chemical Process Quantitative Risk Analysis," Second Edition, American Institute of Chemical Engineers Center for Chemical Process Safety, New York, 2000

5. Dyer J., Raibagkar A., Magenes L., and Anderson T., 2014, "New Control Building Construction Feasibility Analysis," Chemical Engineering Transactions, 36, 103-108

6. Anderson, T., Black, D., Gandhi, M., Raibagkar, A., Hodge, P. "Leveraging Data from a Quantitative Risk Assessment to Determine Blast and Fire Risk to Safety Critical Equipment in the Chemical and Refining Industries," submitted to the 12th Global Congress on Process Safety: 2016 Spring Meeting, April 2016 